\title{
Development of green composites using agricultural waste
}

\author{
T. Ota ${ }^{1} \&$ A. Uehira ${ }^{2}$ \\ ${ }^{1}$ Department of Mechanical Engineering, \\ Toyama National College of Technology, Japan \\ ${ }^{2}$ Advanced Engineering Faculty, \\ Toyama National College of Technology, Japan
}

\begin{abstract}
This study deals with the development and evaluation of environment-friendly composites that are composed of polylactic acid (PLA) resin and rice straw. The rice straw fibers were extracted from rice straw harvested in Toyama city. The preliminary composites were prepared by mixed rice straw fiber and PLA resin, followed by drying at $50^{\circ} \mathrm{C}$ for 24 hours. Rice straw green composites were fabricated by the vacuum assisted hot pressing method. The mould temperature was changed from $150^{\circ} \mathrm{C}$ to $210^{\circ} \mathrm{C}$, in order to investigate the effect of molding conditions on the mechanical properties of rice straw green composites. The molding pressure and time was fixed to $2 \mathrm{MPa}$ and 10 minutes, respectively. The water evaporation rate for rice straw green composites was measured in order to investigate the variation in moisture with respect to the drying time for rice straw fiber or rice straw/PLA composites. The evaporation rate of rice straw/PLA composites was lower than that of rice straw fiber. The flexural strength and modulus increased with increasing the fiber weight fraction of rice straw green composites, and indicated a peak flexural strength and a peak flexural modulus at the molding temperature ranges near $180^{\circ} \mathrm{C}$, the fiber weight fraction $30 \mathrm{wt} . \%$. Keywords: green composites, rice straw, polylactic acid (PLA), vacuum assisted hot press molding, flexural properties.
\end{abstract}

\section{Introduction}

In recent years, natural fiber reinforced thermoplastics (NFRTP) have been gaining considerable attention for their potential contribution to improve 
environmental issues, such as reduction of carbon dioxide emissions and the saving of fossil resources. NFRTP have also attracted interest and have been accepted widely in to the industrial fields, because of their high strength and stiffness, low cost and desirable recycling features [1-3]. The composite industry looks into alternative low cost lignocellulosic sources, which can decrease overall manufacturing costs and increase stiffness of the materials.

Rice straw is one of such major agricultural by-products, which contain cellulose, hemicellulose, lignin, silica and ash. Rice straw is an annually renewable fiber. According to the MAFF, Japan produced 8.5 million tons of rice in 2010 [4]. Most of rice straws are used as livestock feeding and plowing-in. Some rice straws are burned. However, rice straw may not be burned in many prefectures in Japan, because of environment regulation. Use of rice straw and other agricultural by-products as reinforcement in the production of composite materials alleviate the shortage of wood resource. Over past several years, there has been increasing interest in the use of rice straw and wheat straw as a reinforcing filler of wood-plastic composites. Thus, extensive research utilizing wheat straw and rice straw as filler for petroleum-based plastics, such as novolac resin, high-density polyethylene, low-density polyethylene, poly-vinyl alcohol and polypropylene, has been conducted [5-10]. Patil et al. [5] have made a composite material composed of wheat straw filler and polypropylene, and reported their improved mechanical properties. Panthapulakkai and Sain [7] reported that wheat straw filled high-density polyethylene (HDPE) exhibited superior mechanical properties compared to cornstalk, corncob and even wood flour filled HDPE.

In this study, the composites consisting of poly lactic acid (PLA) resin and rice straw fibers have been prepared by a vacuum assisted hot pressing method. Rice straw fibers were extracted from rice straws after rice harvest. The mechanical properties of rice straw fiber and PLA matrix have been examined from a viewpoint of determining the optimum molding condition of vacuum assisted hot pressing. We have also investigated the effect of molding conditions on the mechanical properties of rice straw green composites.

\section{Experimental procedure}

\subsection{Materials}

The matrix polymer used is polylactic acid (PLA, LANDY PL-1000, Miyoshi Oil \& Fat Co., Ltd., Japan). The rice straw fibers were extracted from rice straws harvested in Toyama city. To extract the rice straw fibers, the rice straw was immersed for 3 hours in a solution of $\mathrm{NaOH}$ with $5 \mathrm{~mol} / 1$ concentration at $90^{\circ} \mathrm{C}$. The rice straw fibers were washed in pure water to remove the impurities that remained on the surface of rice straw fiber. The rice straw fibers were dried at $50^{\circ} \mathrm{C}$ for at least 24 hours in order to reduce the effect of the water content of consolidation behavior. Figure 1 shows the appearance and the SEM image of the rice straw fiber. 


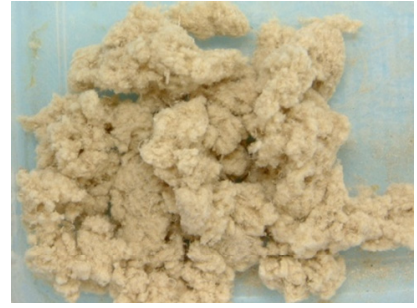

Figure 1: Rice straw fiber.

\subsection{Preparation of preliminary composites}

In order to facilitate the molding of green composites with a hot pressing machine, the preliminary composites were prepared by mixed rice straw fiber and PLA resin using a non-bubbling kneader (NBK-1, Nihonseiki Kaisha, Ltd., Japan), followed by drying at $50^{\circ} \mathrm{C}$ for 24 hours using a drying oven (EPN-115, Isuzu Seisakusho Co., Ltd., Japan). Figure 2 shows a finished preliminary composite material.

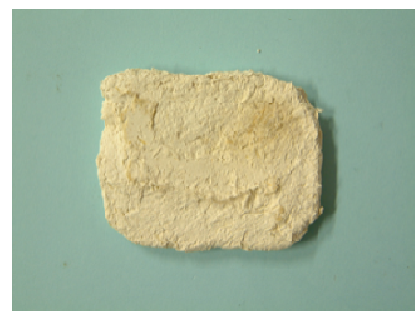

Figure 2: $\quad$ Photograph of preliminary composite.

\subsection{Hot pressing of rice straw green composites}

Figure 3 shows the schematic view of the vacuum assisted hot press molding. The vacuum assisted hot press molding was carried out using a hot pressing machine (AH-2003, As one Co., Ltd., Japan) and a vacuum pump, after setting the preliminary composites in a metallic mould, then covering a mould with the vacuum bag. The molding temperature was changed from $150^{\circ} \mathrm{C}$ to $210^{\circ} \mathrm{C}$. The molding pressure and time was fixed to $2 \mathrm{MPa}$ and 10 minutes, respectively.

\subsection{Flexural testing}

In order to evaluate the mechanical properties of rice straw green composites, the 3-point flexural test was carried out using a universal testing machine (Ez-graph, Shimadzu Co. Ltd., Japan) at room temperature. The dimensions of the specimen are $15 \mathrm{~mm}$ width, $60 \mathrm{~mm}$ length and $2 \mathrm{~mm}$ thickness, respectively. The flexural test was performed under the follow conditions: cross-head speed of $1.0 \mathrm{~mm} / \mathrm{min}$ and span length of $40 \mathrm{~mm}$. 


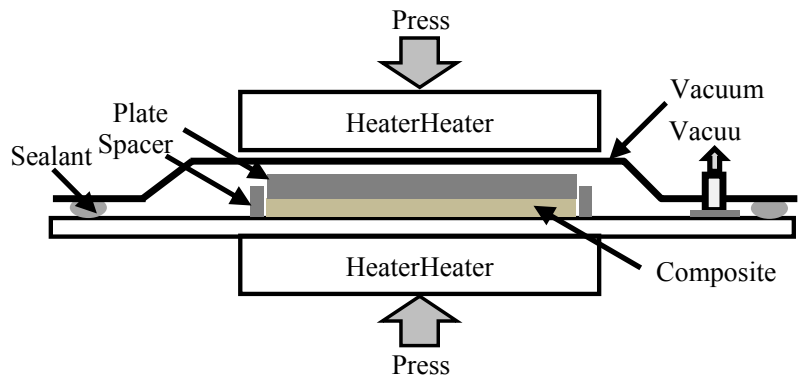

Figure 3: $\quad$ Schematic view of vacuum assisted hot press molding.

\subsection{Water evaporation rate}

Measurement of the water evaporation rate for rice straw green composites was carried out using a moisture analyzer (MOC63u, Shimadzu Co. Ltd., Japan). The temperature and time were set $100^{\circ} \mathrm{C}$ and 1 hour, respectively. The water evaporation rate $R$ is given by the following equation:

$$
R=\frac{M_{W}-M_{D}}{M_{W}} \times 100
$$

where $M_{W}$ is the mass of undried material when measurement starts, $M_{D}$ is the mass of dried materials when measurement ends.

\section{Results and discussion}

\subsection{Water evaporation rate}

Figure 4 shows the variation in the water evaporation rate with respect to the drying time for rice straw fiber and rice straw/PLA composites. The water evaporation curves of both materials showed the similar behavior, which the moisture evaporated rapidly during the first stages $(0-200 \mathrm{sec}$.) reaching a certain value, the saturation point, where no more moisture was evaporated and the content of moisture in the materials remained the same. The evaporation rate of rice straw/PLA composites is lower than that of rice straw fiber because the particles of PLA resin adhere to the rice straw fibers by mixing PLA resin with the rice straw fibers and drying the composites.

\subsection{The effect of fiber weight fraction on flexural properties}

Figure 5 shows the results of flexural tests for rice straw green composites molded at $2 \mathrm{MPa}$ and at $150^{\circ} \mathrm{C}$. The flexural strength increases with increasing the fiber weight fraction, and indicates a peak flexural strength of $83 \mathrm{MPa}$ at the fiber weight fraction near $30 \mathrm{wt} \%$. The maximum flexural strength is 


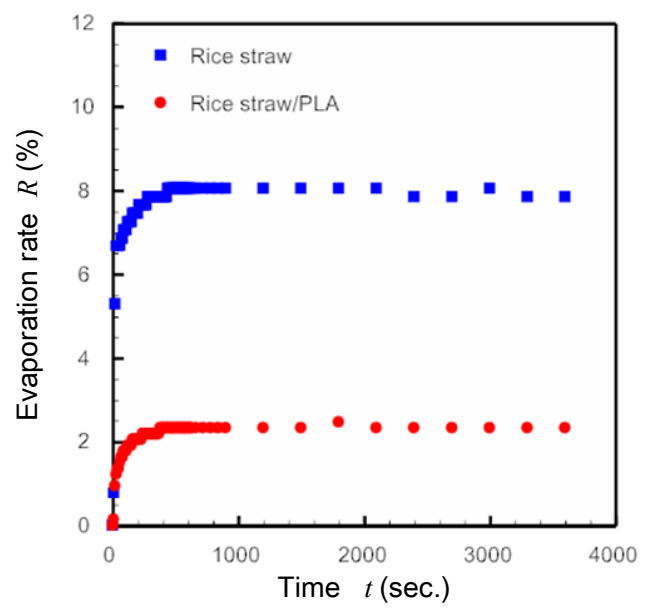

Figure 4: $\quad$ Evaporation rate of rice straw and rice straw/PLA.

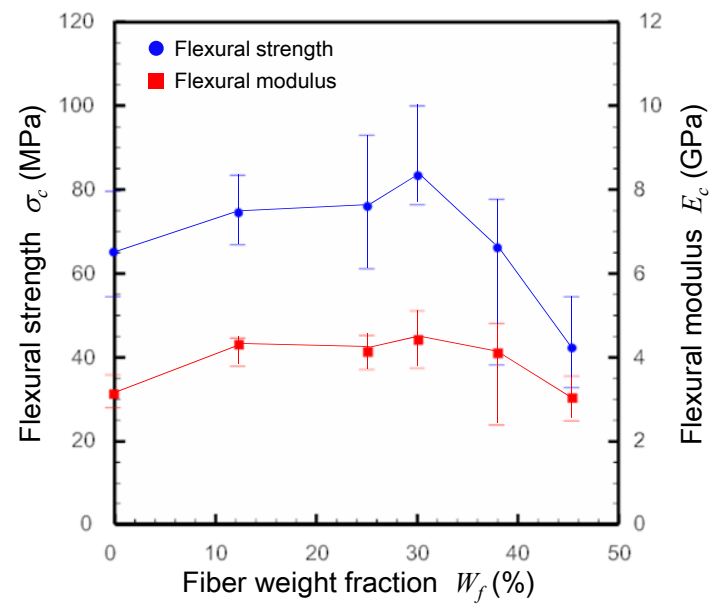

Figure 5: Relationship between flexural strength, flexural modulus of rice straw green composites and fiber weight fraction.

correspondent to 1.3 times the strength of PLA resin. It is proven that the flexural modulus also shows a similar dependence with increasing the fiber weight fraction. The maximum flexural modulus is correspondent to 1.4 times the flexural modulus of PLA resin. However, the composites with a high content of rice straw fibers (over $30 \%$ by weight) showed lower flexural strength than that without the addition. Figure 6 shows the SEM images of the fracture surface 
of rice straw green composites specimens in the flexural test. Extensive debonding, clean rice straw fibers and some voids, indicating the poor fiber/matrix adhesion, can be found in all the specimens. The observation result suggests that the poorer stress transfer at fiber/matrix interface caused the decrease in strengths of the composites. As the reasons for the deterioration of interfacial adhesion, it is supposed that the PLA matrix didn't fully permeate to the inside of rice straw green composites due to the high viscosity of PLA matrix and the poor wettability on the fiber surface. Moreover, the rice straw fibers contain moisture, because the preliminary composites were fabricated by kneading rice straw fiber and water-dispersion type PLA resin. Then, although the preliminary composites were fully dried, moisture has been included in the preliminary composites. The moisture contained in preliminary composites or rice straw evaporates by heating of hot pressing. Therefore, it is supposed that the steam made damage easy to occur in fiber/matrix interface by giving pressure to resin surrounding a fiber, and that hydrolysis of PLA matrix in the vicinity of the rice straw fibers occurred by the reaction with the moisture, which remained in rice straw fibers or preliminary composites during the course of heating.

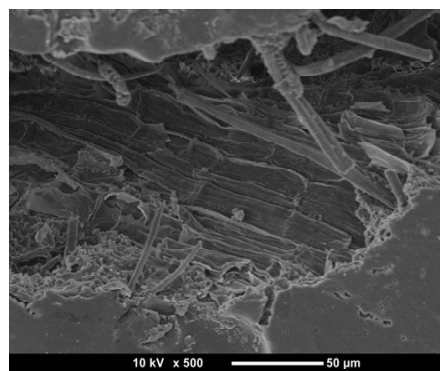

(a) $12 \mathrm{wt} . \%$

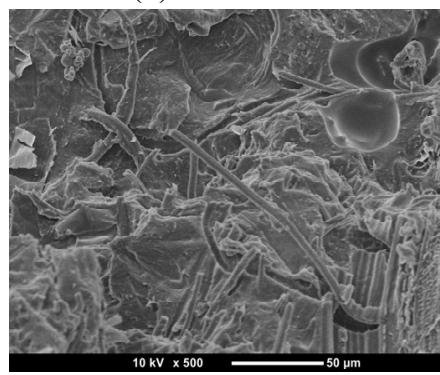

(c) $30 \mathrm{wt} . \%$

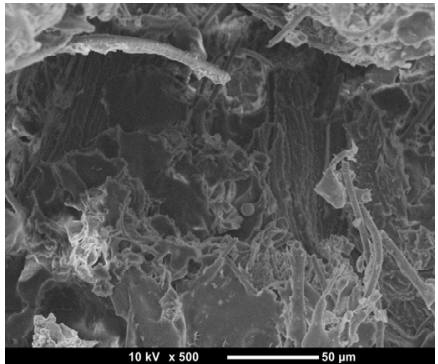

(b) 25 wt. $\%$

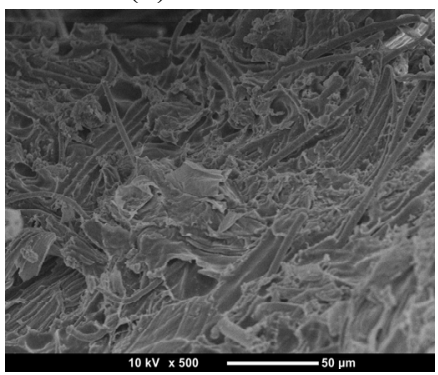

(d) $40 \mathrm{wt} . \%$

Figure 6: SEM images of fracture surface of rice straw green composites. (Molding temperature $150^{\circ} \mathrm{C}$.)

\subsection{The effect of heat treatment on mechanical properties of fiber, matrix}

In order to establish the most suitable molding condition, the mechanical properties of rice straw fiber and PLA matrix were determined. Figure 7 shows 
the Weibull plots for the tensile strength of rice straw fibers with varying temperature. The Weibull shape and scale parameters as well as mean, standard deviation and correlation coefficient computed from these Weibull distributions are listed in Table 1. The average tensile strength of rice straw fibers heat-treated at $150^{\circ} \mathrm{C}$ is $136.2 \mathrm{MPa}$. The tensile strength of rice straw fibers heat-treated at $180^{\circ} \mathrm{C}$ is similar to that of rice straw fibers heat-treated at $150^{\circ} \mathrm{C}$. However, the tensile strength of rice straw fibers heat-treated at $210^{\circ} \mathrm{C}$ markedly decreases as compared with that of rice straw fibers heat-treated at $180^{\circ} \mathrm{C}$. The tensile strength drops about $30 \%$ from $142.8 \mathrm{MPa}$ down to $98.0 \mathrm{MPa}$. Figure 8 shows the effect of molding temperature on the flexural properties of PLA matrix. It is obvious that the flexural modulus does not decrease even with higher molding temperature, while the flexural strength indicates a peak flexural strength of $48.5 \mathrm{MPa}$ at molding temperature range $180^{\circ} \mathrm{C}$, decreases with the rise of molding temperature above $180^{\circ} \mathrm{C}$. Based on these results, the processing temperature for molding rice straw green composites should be kept below $180^{\circ} \mathrm{C}$ in order to prevent strength reduction due to thermal degradation.

Table 1: Weibull parameters and factors of tensile strength of rice straw fibers with the various treated temperatures.

\begin{tabular}{|c|c|c|c|c|c|}
\hline $\begin{array}{c}\text { Treated } \\
\text { temperature } \\
\left({ }^{\circ} \mathrm{C}\right)\end{array}$ & $\begin{array}{c}\text { Shape } \\
\text { parameter } \\
\alpha\end{array}$ & $\begin{array}{c}\text { Scale } \\
\text { parameter } \\
\sigma_{0}\end{array}$ & Mean & $\begin{array}{c}\text { Standard } \\
\text { deviation } \\
\text { SD }\end{array}$ & $\begin{array}{c}\text { Correlation } \\
\text { coefficient } \\
R\end{array}$ \\
\hline 150 & 3.11 & 152.2 & 136.2 & 47.3 & 0.989 \\
\hline 180 & 4.24 & 157.0 & 142.8 & 37.3 & 0.975 \\
\hline 210 & 2.59 & 110.4 & 98.0 & 40.4 & 0.954 \\
\hline
\end{tabular}

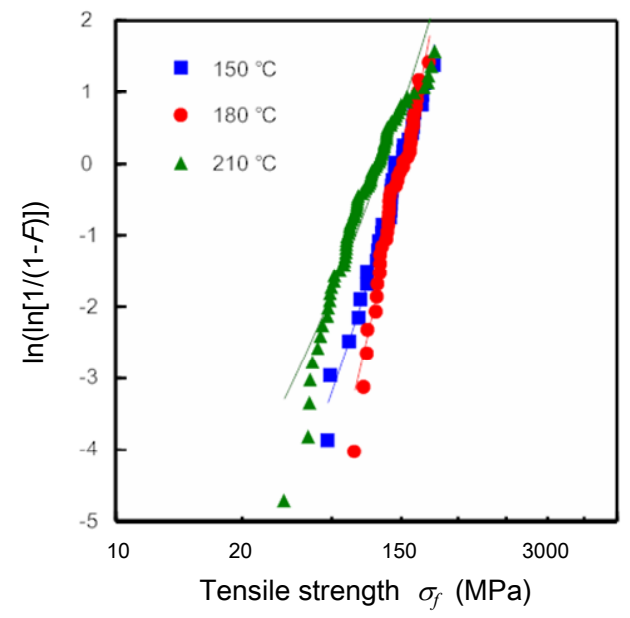

Figure 7: Weibull distribution plots for tensile strength of rice straw fiber with varying temperature. 


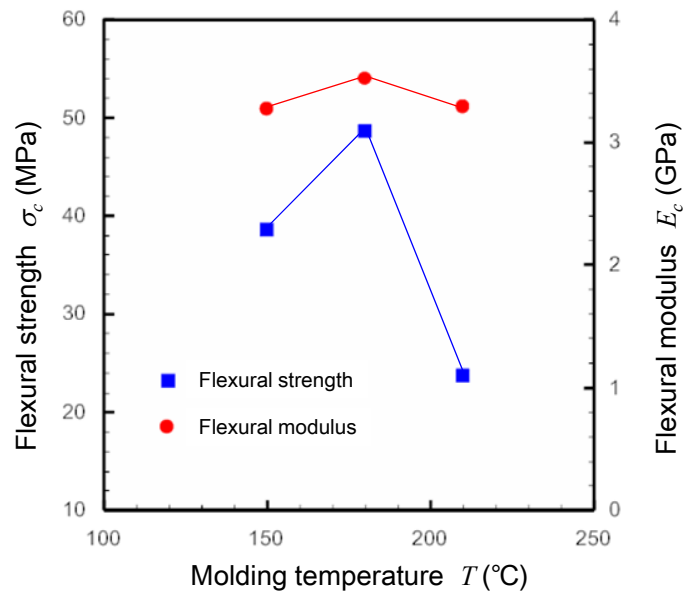

Figure 8: Relationship between flexural strength, flexural modulus of PLA and molding temperature.

\subsection{The effect of molding temperature on flexural properties}

Figure 9 describes the change of flexural properties according to the molding temperature. The flexural strength and the flexural modulus of rice straw green composites indicate a peak value at the molding temperature range of $180^{\circ} \mathrm{C}$. The flexural strength and the flexural modulus of rice straw composites molded at $180^{\circ} \mathrm{C}$ are approximately $94 \mathrm{MPa}$ and $5 \mathrm{GPa}$, respectively, which are $12 \%$ higher than those at $150^{\circ} \mathrm{C}$. However, the green composites with a high molding

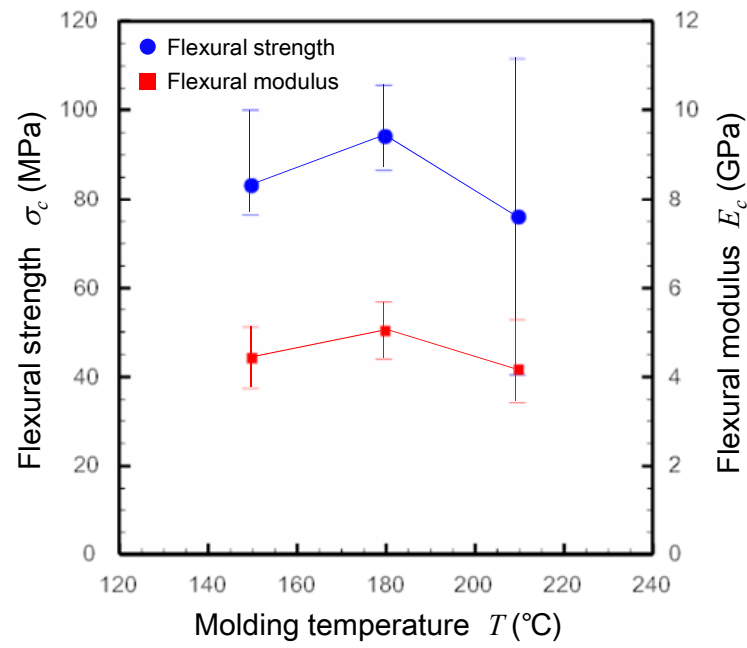

Figure 9: Relationship between flexural strength, flexural modulus of rice straw green composites and molding temperature. 
temperature above $180^{\circ} \mathrm{C}$ showed lower flexural strength and modulus than that with a molding temperature at $180^{\circ} \mathrm{C}$. Figure 10 shows the $\mathrm{SEM}$ images of the fracture surface of rice straw green composites, which contain $30 \mathrm{wt} \% \%$ rice straw fiber. The adhesion between the rice straw and PLA matrix in the rice straw green composites molded at $180^{\circ} \mathrm{C}$ seems to be better than that molded at $150^{\circ} \mathrm{C}$, and the rice straw fibers are imbedded in the PLA matrix, which indicates good wetting by the polymer. The rise of molding temperature can be effective for the improvement of the mechanical properties of rice straw green composites, because the viscosity of PLA matrix became lower, and PLA matrix fully permeate to the inside of rice straw green composites. However, the fracture surface of rice straw green composites molded at $210^{\circ} \mathrm{C}$ seems to be rough. This observation result suggests that the rise of molding temperature caused the decrease in strengths of the composites due to thermal degradation as discussed in section 3.3. In addition, debonding or clean rice straw fibers can be found in all the green composites. It is proven that the bonding between rice straw fiber and PLA matrix was not so improved even if the green composites were molded at the optimum condition.

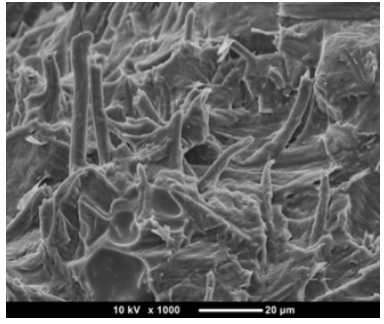

(a) $150^{\circ} \mathrm{C}$

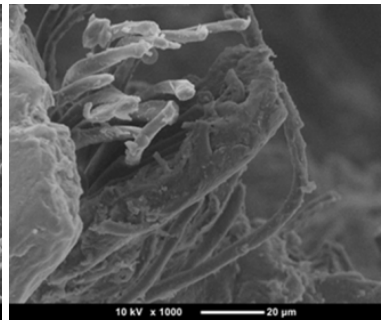

(b) $180^{\circ} \mathrm{C}$

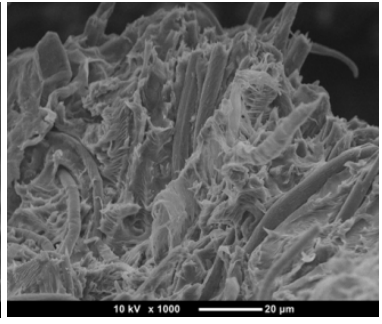

(c) $210^{\circ} \mathrm{C}$

Figure 10: SEM images of fracture surface of rice straw green composites. (Fiber weight fraction 30wt.\%).

\section{Conclusion}

The mechanical properties of rice straw green composites fabricated by a vacuum assisted hot press molding have been investigated. Summarized results and remarks are as follows.

1) The water evaporation curves of both materials showed the similar behavior. The evaporation rate of rice straw/PLA composites is lower than that of rice straw fiber.

2) The flexural strength increases with increasing the fiber weight fraction, and indicates a peak value at the fiber weight fraction near $30 \mathrm{wt} . \%$.

3) The optimum molding temperature is $180^{\circ} \mathrm{C}$ among the conditions investigated.

4) The flexural strength and flexural modulus obtained are approximately $94 \mathrm{MPa}$ and $5 \mathrm{GPa}$, respectively. This flexural strength is $12 \%$ higher than that of rice straw green composites molded at $150^{\circ} \mathrm{C}$. 


\section{Acknowledgement}

This study was supported by the Research and Development Center for Composite Materials at Doshisha University, by Mita trading Co., Ltd., Japan

\section{References}

[1] Nabi Saheb, D. and Jog, J. P., Natural fiber polymer composites: A review, Advances in Polymer Technology, 18(4), pp. 351-363, 1999.

[2] Herrera-Franco, P., Valadez-Gonzalez, A., Cervantes-Uc, M., Development and characterization of a HDPE-sand-natural fiber composite, Composites Part B, 28(3), pp. 331-343, 1997.

[3] Oksman, K., Skrifvars, M., Selin, J.F., Natural fibres as reinforcement in polylactic acid (PLA) composites, Compos. Sci. Tech., 63(9), pp. 13171324, 2003.

[4] Ministry of Agriculture, Forestry and Fisheries (MAFF) homepage, www.maff.co.jp

[5] Patil, Y.P., Gajre, B., Dusane, D., Chavan, S., Mishra, S., Effect of maleic anhydride treatment on steam and water absorption of wood polymer composites prepared from wheat straw, cane bagasse, and teak wood sawdust using novolac as matrix, J. of Appl. Polym. Sci., 77(13), pp. 29632967, 2000.

[6] Schirp, A., Loge, F., Aust, S., Swarier, P., Turner, G., Wolcott, M., Production and characterization of natural fiber-reinforced thermoplastic composites using wheat straw modified with the fungus Pleurotus ostreatus, J. Appl. Polym. Sci., 102(6), pp. 5191-5201, 2006.

[7] Panthapulakkai, S., Sain, M., Agro-residue reinforced high-density polyethylene composites: fiber characterization and analysis of composite properties, Compos. Part A, 38(6), pp. 1445-1454, 2007.

[8] Wang, Z., Wang, Z., Ren, Y., Synthesis and characteristics of interfacial coupling agents for agro-residues/recycled plastics composite, Chem. Ind. Forest Prod., 27(1), pp. 67-71, 2007.

[9] Alemdar, A., Oksman, K., Sain, M., The effect of decreased fiber size in wheat straw/polyvinyl alcohol composites, J. Biobased Metar. Biol., 3(1), pp. 75-80, 2009.

[10] Yang, H.S., Kim, H.J., Son, J., Park, H.J., Hwang, T.S., Rice-husk flour polypropylene composites: mechanical and morphological study, Compos. Struct., 63, pp. 305-312, 2004. 